\title{
Configurações
}

Revista de sociologia

\section{Arte e Pós-verdade: A questão especular do ponto de vista filosófico, político e das ciências humanas}

Art and Post-truth: The specular question from the philosophical, political and human science point of view

Art et post-vérité : la question spéculaire du point de vue des sciences

philosophiques, politiques et humaines

\section{Rui Mourão}

\section{(2) OpenEdition}

\section{Journals}

Edição electrónica

URL: http://journals.openedition.org/configuracoes/6330

DOI: $10.4000 /$ configuracoes. 6330

ISSN: 2182-7419

\section{Editora}

Centro de Investigação em Ciências Sociais

Edição impressa

Paginação: 31-49

ISSN: 1646-5075

\section{Refêrencia eletrónica}

Rui Mourão, «Arte e Pós-verdade: A questão especular do ponto de vista filosófico, político e das ciências humanas », Configurações [Online], 22 | 2018, posto online no dia 28 janeiro 2019, consultado o 19 abril 2019. URL : http://journals.openedition.org/configuracoes/6330 ; DOI : 10.4000/ configuracoes. 6330 
Mourão, Rui - Arte e Pós-verdade: A questão especular do ponto de vista filosófico, político e das ciências humanas. Configurações, vol. 22, 2018, pp. 31-49.

\title{
Arte e Pós-verdade: A questão especular do ponto de vista filosófico, político e das ciências humanas
}

RUI MOURÃO*

FCSH - Universidade Nova de Lisboa

\begin{abstract}
Resumo
O artigo apresenta uma reflexão sobre a relação da arte com a noção de verdade a partir das problemáticas de representação, identidade e poder. Uma abordagem filosófica contrapõe à referência aristotélica de busca de verdade na arte, o questionamento foucaultiano do "regime de verdade" e a Pós-verdade. Segue-se um enquadramento histórico e político das relações da arte com paradigmas de Trans-verdade, Anti-verdade e Pós-verdade. Focam-se consequências do Pós-modernismo e Pós-verdade no esvaziamento de impacto das artes visuais. Propõe-se em alternativa um compromisso criativo laboratorial de Bio-verdade. Conclui-se com uma perspetiva científica sobre: o poder da metáfora, o paradoxo artístico de condensação/expansão e a arte como espelho.
\end{abstract}

Palavras-chave: arte, verdade, pós-verdade, espelho, poder.

\begin{abstract}
Art and Post-truth: The specular question from the philosophical, political and buman science point of view

The article presents a reflection regarding the relationship between art and the notion of truth based on the problems of representation, identity and power. A philosophical approach contrasts with the Aristotelian reference of the search for truth in art, the Foucauldian questioning of the "regime of truth" and Post-truth. It is followed by a historical and political framework of the relationships of art with paradigms of Transtruth, Anti-truth and Post-truth. The consequences of Postmodernism and Post-Truth are focused on emptying the impact of visual arts. Alternatively, a creative laboratory commitment to Bio-truth is proposed. It concludes with a scientific perspective on: the power of metaphor, the artistic paradox of condensation/expansion, and art as a mirror.
\end{abstract}

Keywords: art, truth, post-truth, mirror, power.

\footnotetext{
*E-mail: mourao.rui@gmail.com
} 


\section{Résumé}

Art et post-vérité : la question spéculaire du point de vue des sciences philosophiques, politiques et humaines

L'article présente une réflexion sur les relations entre l'art et la notion de vérité à partir des problèmes de représentation, d'identité et de pouvoir. Une approche philosophique contraste avec la référence aristotélicienne de la recherche de la vérité dans l'art, le questionnement foucaldien du "régime de la vérité » et la post-vérité. Il s'inscrit dans un cadre historique et politique des relations de l'art avec les paradigmes de la vérité trans, de l'anti-vérité et de la post-vérité. Les conséquences du postmodernisme et de la post-vérité sont centrées sur la suppression de l'impact des arts visuels. En alternative, un engagement créatif de Bio-vérité est proposé. L'article se termine par une perspective scientifique sur le pouvoir de la métaphore, le paradoxe artistique de la condensation/expansion et l'art en tant que miroir.

Mots-clés: art, vérité, post-vérité, miroir, pouvoir.

\section{Mimesis, da busca filosófica à recusa política}

$\mathrm{Na}$ tradição pré-moderna a produção artística enquadrava-se claramente na perspetiva aristotélica da mimesis, a qual foi estruturante para a valorização das artes (oposta à perspetiva platónica de mimesis que desvalorizava a arte como imitação do mundo das ideias e, portanto, aparência das aparências afastada do real). A arte enquanto imitação, segundo Aristóteles, variava em relação aos meios, objetos ou modos, mas direta ou indiretamente, se bem feita, constituía-se como representação reveladora. Na sua obra Poética, o ênfase é dado à representação das ações, pela dimensão trágica, heróica e mítica, segundo princípios de verossimilhança e necessidade (Aristóteles, 1984: 249) que envolviam "peripécias”, ou seja, "mutação dos sucessos no contrário", e "reconhecimento" pela "passagem do ignorar ao conhecer" (Aristóteles, 1984: 250). A criação de imitações sublimadoras de referências míticas visa neste enquadramento identificar valores superiores universais (o próprio modelo de narrativa aristotélica é um todo com princípio, meio e fim), onde "importa seguir o exemplo dos bons retratistas, os quais, ao reproduzir a forma peculiar dos modelos, respeitando embora a semelhança, os embelezam" (Aristóteles, 1984: 255). Na sua representação dos caracteres humanos "devem os poetas sublimá-los, sem que deixem de ser o que são" (Aristóteles, 1984: 255). Neste paradigma as representações do visível e do não visível, em última instância, procuram levar a uma catarse das emoções envolvidas com vista a uma purificação. Por se entender que algo mais profundo ou transcendente em relação àquilo que representa se dá a conhecer, a reconhecer. Tal noção vai ser estrutural na dimensão filosófica da arte como simulacro especular criado pelo artista com características sublimadoras exigentes, mas clarificadoras, intensas, verdadeiras. 
Pelo contrário, na perspetiva filosófica contemporânea há uma desconstrução da própria noção de verdade, questionando-se até que ponto a sua perceção depende da relação de forças dominantes num determinado contexto. Segundo Michel Foucault, um dos mais influentes autores na formação do pensamento contemporâneo, são as relações de poder na sociedade que determinam sempre um "regime de verdade" (Foucault, 1975). Enumeram-se uma série de conhecimentos, discursos e técnicas que sustêm um sistema de disciplina e punição ao desvio, instituindo como construção política a conveniente e sustentável verdade aceite e reproduzida. Estabelece-se a ideia de que o poder molda a construção de um sistema de validação de verdades e é moldado por essa mesma construção. Partindo do princípio de que o regime de verdade molda a própria subjetividade é o próprio sujeito que se apresenta descentralizado da produção de saber. Numa "história crítica do pensamento" (Foucault, 1994: 632) que é uma "história do pensamento como pensamento da verdade" (Foucault, 1994: 669), questiona-se em última instância a possibilidade do sujeito chegar ao conhecimento. Seja pela religião, pela ciência ou pela poesia. Comparando a tradicional abordagem aristotélica com a pós-moderna perspetiva foucaultiana, verificamos que onde a arte se apresentava como busca mítica de verdade, se sobrepõe a ideia da arte como mito de verdade ao serviço do poder.

Num pensamento pós-moderno onde a noção de verdade perdeu em grande medida a sua validade, reduzida a instrumental construção de poder, como pode a arte ser revelação sublimadora de conhecimento? Como pode esta se relacionar com a verdade num contexto cultural onde, inclusive o próprio acesso à realidade é permanentemente mediado por uma enorme proliferação de imagens trabalhadas, frequentemente manipuladas com fins económicos e políticos?

De forma paradigmática, surgiu recentemente - e rapidamente se expandiu - um novo conceito que espelha a situação atual. Na habitual eleição do Oxford Dictionaries para palavra internacional do ano, a escolhida para 2016 foi: Pós-verdade. Os editores do dicionário definiram-na como "relativa ou denotando circunstâncias em que factos objetivos são menos influentes na formação da opinião pública do que apelos à emoção e crença pessoal"1.

A palavra composta pós-verdade exemplifica uma expansão no significado do prefixo pós- que tem obtido uma crescente proeminência em anos recentes. Em vez de simplesmente se referir ao tempo depois de uma específica situação ou evento — como em pós-guerra ou pós-jogo — o prefixo em pós-verdade tem um significado mais como "pertencente

1 Informação disponibilizada pelos editores do Oxford Dictionaries. Tradução minha. Fonte: https:// en.oxforddictionaries.com/word-of-the-year/word-of-the-year-2016 
a um tempo em que o conceito específico se tornou sem importância ou irrelevante". Esta nuance parece ter origem em meados do séc. XX, em formações como pós-nacional (1945) ou pós-racial (1971). Pós-verdade crê-se ter sido usada com este sentido pela primeira vez num ensaio de 1992 pelo tardio dramaturgo servo-americano Steve Tesich na revista Nation. Refletindo sobre o escandaloso caso do Irão-Contras e a Guerra do Golfo, Tesich lamentou que "nós, como pessoas livres, decidimos livremente que queremos viver num certo mundo de pós-verdade. Há evidências da expressão “pós-verdade" ser usada antes do artigo de Tesich, mas aparentemente com o sentido transparente de "após a verdade ter sido conhecida" e não com a nova aplicação de que a verdade em si se tornou irrelevante ${ }^{2}$.

Há aqui duas deduções importantes. Por um lado, o relativismo pós-moderno - descrente da verdade como elemento objetivo - é já um pensamento partilhado em tão larga escala num Ocidente em crise de valores, que se cria até um neologismo que implica que a verdade se tornou irrelevante num tempo de abundantes pós-. Por outro lado, note-se que a palavra pós-verdade é geralmente usada de forma depreciativa, revelando que simultaneamente emerge um posicionamento crítico que busca que a relação com a informação e a verdade seja descolonizada da sua instrumentalização pelo poder. Há maior necessidade pública de consciência ética/moral por uma reaproximação das conceções do mundo à realidade ${ }^{3}$. Estamos portanto diante de um paradoxo entre descrença e necessidade de acreditar.

Em termos artísticos, que implica este conflito existencial e civilizacional? Que repercussões tem na relação da arte com as construções representacionais de verdade e poder? Em última instância, que ambição filosófica pode a arte ter e que posicionamento(s) político(s) deve adotar?

\section{Breve enquadramento histórico das relações da arte com a verdade e o poder}

Em termos temporais, cada época tem o seu "regime escópico" (Baxandall, 1972: 45-138), refletindo diferentes ontologias consoante o "olho da época" (Baxandall, 1972: 45-138). A arte que é feita em cada momento histórico projeta sempre o olhar do ser humano dessa época. Funcionando essa posição como scopia, no sentido etimológico de ato ou instrumento que dá a ver algo à partida ininteligível, tal permite perceber a(s) verdade(s) do momento, isto é,

2 Idem.

3 Realidade enquanto "qualidade pertencente aos fenómenos com que reconhecemos haver uma existência independente da nossa vontade" (Berger, 2004). 
a(s) crença(s) vigente(s). As quais dependem sempre de várias causas e efeitos. De vários contextos, motivações e condicionamentos. De inúmeras forças motrizes. Frequentemente complexas, diversificadas e até contraditórias, mas cujo balanço, cujo flexível eixo de ajustamento, obriga a uma permanente dinâmica de construção e destruição da identidade do ser humano, à qual as expressões da construção cultural a que se convencionou chamar de arte automaticamente reagem ou precedem. É como se a arte fosse um barómetro, um indicador do sentido para onde a cada presente tende ou pretende tender o ser humano. Cada ser humano. Funciona socialmente como um abstrato rizoma de eixos para onde tende $(\mathrm{m}) \mathrm{o}(\mathrm{s})$ estado(s) com que se identifica cada artista e a sociedade no seu todo. A arte reflete, portanto, sínteses (e variações) dos sentimentos, questões e posicionamentos que constroem os indivíduos e as sociedades de cada época. Claro, que a cada presente a arte passada vai simultaneamente sendo interpretada segundo a sobreposição do regime escópico do momento.

Ao longo dos tempos deram-se pois mudanças na relação do ser humano com a arte (do presente e do passado) em consequência das mudanças de relação com o poder e a noção de verdade. Essas mudanças intensificaram-se exponencialmente a partir da Modernidade, a qual pode ser tomada como referência civilizacional pela sua ruptura maior com verdades absolutas e identidades definidas. Nesse sentido, pode-se estabelecer uma divisão histórica em 3 grandes enquadramentos para a conceção de arte: Pré-modernidade, Modernidade e Pós-modernidade. O percurso faz-se desde a exaltação de verdades em prol de Deus e dos poderes pré-modernos, seguindo pelo questionamento ao poder e à identidade feito pelas vanguardas modernistas, até chegarmos à pós-moderna conceptualização de pós-verdades. Como critério para esta organização conceptual aplicam-se os princípios da Sociologia e da Antropologia, que percecionam a obra de arte como "testemunho de uma relação social” (Baxandall, 1991: 11) e dum "sistema cultural” (Geertz, 2000).

Pode-se então sistematizar o seguinte esquema, com 3 grandes paradigmas históricos:

- Paradigma Pré-moderno: a arte como transcendência de verdades - A representação simbólica como meio sublimador do poder - A emancipação da representação simbólica como arte do sublime

Paradigma artístico de verdade: Trans-verdade (num imaginário de sublimação).

- Paradigma Moderno: a arte como ruptura de verdades

- Da ruptura com a tradição à ruptura com as utopias

- As vanguardas artísticas como ruptura contra-verdade

Paradigma artístico de verdade: Anti-verdade (numa prática de ruptura). 
- Paradigma Pós-moderno: a arte como conceptualização de pós-verdades

- O relativismo pós-moderno e o triunfo da pós-verdade

- A arte como especulação conceptual e capitalista

Paradigma artístico de verdade: Pós-verdade (numa narrativa de conceptualização).

Historicamente, a arte tem as suas raízes ligadas ao sagrado e a representação simbólica era um meio de sublimar a ligação do terreno ao transcendente. Podemos apelidar este paradigma escópico pré-moderno de Trans-verdade, tendo em conta que a verdade era algo transcendente ao ser humano e a arte uma busca de o aceder, de elevar o ser humano. Daí que a arte (ou o que identificamos atualmente como arte) tenha sido usada como meio de representação mística (provavelmente das pinturas e objetos para rituais pré-históricos até seguramente às imagens que a igreja católica usava nos seus templos para representar histórias da bíblia ou de santos a uma população maioritariamente analfabeta), mas também como meio de legitimação de poderes, tanto religiosos como profanos. O extraordinário encantamento da beleza dos objetos e das imagens (note-se que a própria origem etimológica da palavra imagem está ligada à de magia ${ }^{4}$ ), num mundo onde as imagens eram escassas, servia para colocar os membros da aristocracia e do poder real, assim como do clero e mais tarde da burguesia, sublimados de forma simbólica. A estética era apropriada e trabalhada para exaltar os poderosos acima da vulgaridade do povo ligado em grande medida à terra e ao trabalho físico. A estética do sublime visava legitimar - sublimar - a excecionalidade de personalidades e classes sociais face aos restantes mortais. Em suma, no paradigma pré-moderno a arte tinha a função de exaltação de conceções claras e bem definidas do mundo e dos poderes que o regiam.

É com o Renascimento, movimento fundador da Modernidade, com o teocentrismo a ser substituído pelo antropocentrismo e um maior domínio do princípio da razão e do individual, que os artistas começam a assinar as suas imagens, as suas obras. Procuram desligar-se duma mera atividade técnica de ofício artesanal para através da arte procurarem uma via de explorar caminhos próprios ligados ao conhecimento intelectual (sobretudo científico e filosófico), recuperando o legado cultural da Antiguidade Clássica (incluindo a Poética de Aristóteles). Desde então, ao longo de séculos, os artistas foram intelectualmente ganhando um reconhecimento crescente como autores, tendo 
o Romantismo se empenhado em emancipar a arte de servir o sublime aos poderosos para se afirmar enquanto "arte pela arte" .

[...] devemos olhar para toda a arte do passado pré-moderno, não efetivamente como arte, mas como design. De facto, os antigos gregos falavam de "techne" — sem diferenciar arte de tecnologia. Se olharmos para a arte da antiga China, encontramos instrumentos bem desenhados para cerimónias religiosas e para o quotidiano de funcionários da corte e intelectuais. $\mathrm{O}$ mesmo pode ser dito em relação à arte do Antigo Egipto e do Império Inca: não é arte no moderno sentido da palavra, mas design. E o mesmo pode ser dito acerca da arte dos Antigos Regimes da Europa antes da Revolução Francesa - onde também apenas encontramos design religioso, ou o design do poder e da riqueza(Groys, 2014) ${ }^{6}$.

O desejo de liberdade e autonomia dos artistas face aos poderes dominantes (em conexão com os ideais libertários do Iluminismo que inclusive levaram à Revolução Francesa e Americana e às suas réplicas não só no continente europeu, como na luta anti-colonial) veio extremar-se nas rupturas radicais das chamadas vanguardas históricas do séc. XX. Institui-se portanto ao longo de toda a Modernidade um paradigma escópico onde a arte adota um papel oposicionista de Anti-verdade face às tradicionais verdades estabelecidas que serviam a manutenção do status quo.

Enquanto as rupturas faziam o seu caminho, os projetos políticos e económicos modernistas das sociedades burguesas geravam choques nacionalistas com terríveis conflitos armados: as grandes guerras mundiais. Entretanto, ampliava-se a reverberadora expansão da mais estrondosa ruptura da Humanidade com a crença de verdade - a "morte de Deus" — declarada por Nietzsche em 1882. Ao ateísmo da ideia de verdade desvinculada de Deus, mas dependente da perspetiva humana, seguiu-se o niilismo do questionamento ou desvalorização de todos os valores e a supressão da própria possibilidade de verdade.

Entre a busca de liberdade e originalidade, a recusa da sociedade burguesa e a descrença pela "morte de Deus", caem todos os cânones da arte. No séc. $\mathrm{XX}$ conceitos como a figuração, a perspetiva, o virtuosismo técnico ou a beleza são não só postos em causa (num processo começado a esboçar no séc. XIX), como são desconstruídos ou mesmo destruídos, recusando representações identitárias de padrões únicos, tradicionais, dominantes ou elitistas. As linguagens incorporam respostas fraturantes e diversas: o infantil, o "primitivo", o "em 
movimento", o multiperspetivista cubista, o abstrato, o grotesco, o minimal, o pop, etc. Frequentemente os artistas têm inclusive recusado serem catalogados pela História da Arte (Belting, 1987). No fundo, as artes afirmam-se como questionamento e contra-cultura (não obstante também sempre terem existido artes comerciais e de regime, a própria contra-cultura ser comercializada e tudo se contaminar constantemente). Fruto e adubo deste contexto, a relação da arte com a realidade, com o poder e com a identidade tem sido problemática na Modernidade.

As políticas da arte moderna e contemporânea são as políticas da não-identidade. É uma arte que diz ao seu espectador: Não sou o que pensas que sou (em total contraste com: eu sou aquilo que sou). $\mathrm{O}$ desejo de não-identidade é, na realidade, um genuíno desejo humano - os animais aceitam a sua identidade mas os animais humanos não. É neste sentido que podemos falar da paradigmática, representativa função da arte e do artista(Groys, 2016) ${ }^{7}$.

O desencanto com as grandes narrativas ideológicas após a II Guerra Mundial (mais à Direita) e a queda do Muro de Berlim (mais à Esquerda), tornaram o materialismo em algo hegemónico (aliado no Ocidente à Democracia, apesar desta ser limitada pelo próprio Capitalismo que privilegia os detentores de capital). Unido ao desencanto utópico e ao aprofundamento da autonomia individual, emerge um pós-modernismo que tudo coloca num prisma subjetivo e relativo. Em paralelo, e uma vez que a Filosofia e os movimentos artísticos anteriores já tinham derrubado tudo o que eram critérios de aferição de valor, cresce o movimento conceptual, que faz do discurso o grande legitimador da arte (em crescendo desde os ready-made's de Duchamp). É o tempo da exponencial especulação financeira da arte, onde a criação artística é em grande medida tomada nos seus ideais libertários ou de busca de sentido, mas estimulada na sua produção e circulação. À conceptualização da arte (que já não acredita em verdades inerentes e as reconstrói conceptualmente) e à especulação do seu valor pelo mercado, soma-se na sociedade a crescente mediatização da perceção do mundo por imagens. O que ocorre primeiro com os órgãos de comunicação social de massas e posteriormente com a virtualidade da internet, numa avassaladora criação de imagens produtoras de informação simultaneamente múltipla (como retirar uma verdade única entre milhões de conteúdos?) e manipulada (em larga escala por poderes económicos e políticos). É nesta efervescente pós-verdade mediatizada que também a arte deixa de ter como legitimação qualquer critério que lhe seja verdadeiramente intrínseco, mas sim 
os critérios da sua mediatização. No atual paradigma escópico de Pós-verdade os critérios mediadores que regem a arte são: institucionalização (se está dentro dum espaço artístico está validado como arte, sendo o topo o museu e dentre estes os museus de topo), mercantilização (se o preço é alto a arte é boa, o que estimula o marketing capitalista aliado ao status social e permite uma enorme especulação financeira) e discurso (se mediada por um discurso conceptual convincente, frequentemente retórico e com um jargão próprio, a arte contemporânea é legitimada, e com ela os seus produtores e mediadores, ou seja, artistas e curadores) ${ }^{8}$.

\section{Verdade, emoção e afeção: um esvaziamento estético}

"A questão central a ser colocada sobre arte é a seguinte: é a arte capaz de ser um medium de verdade? Esta questão é central para a existência e sobrevivência da arte pois se a arte não puder ser um medium de verdade então a arte é apenas uma questão de gosto. Há que aceitar a verdade mesmo se não agradar. Mas se a arte for apenas uma questão de gosto, então o espectador de arte torna-se mais importante que o produtor de arte. Nesse caso a arte pode ser tratada apenas sociologicamente ou em termos do mercado da arte — não tem independência, não tem poder. A arte torna-se idêntica ao design"(Groys, 2016) ${ }^{9}$.

Ainda que em cada obra e ao longo dos séculos a arte como representação se questione e renove, se desdobre e multiplique, se desconstrua e reconstrua, não se pode apagar o seu ADN cultural. De acordo com Umberto Eco uma obra de arte mesmo em ruptura com normas anteriores, não pode romper com todas, se quer ainda assim ser reconhecida como arte (Kirchof, 2008: 5). Tal deixa um fio condutor entre a Pré-modernidade, a Modernidade e a Pós-modernidade - mesmo se encoberto e exponencialmente rizomático - que transporta um património genético de época para época e de artista para artista, apesar de constantes mudanças conceptuais e de inúmeras variações formais. É uma representação da imaginação que induz pensamento, fluindo no sensível, sem ser um tipo de encriptamento que estabeleça conceitos definitivos ou que sequer possa ser meramente inteligível pela linguagem (Kant, 1951 [1790/93]: 49).

No mundo moderno e pós-moderno, apesar de fortes rupturas com a tradição, a noção de arte como simulacro para chegar ao autêntico e ao mais profundo, foi continuando a operar, mesmo se sob formas diversas e cada vez mais

8 Consultar estudo sobre International Art English, tendo em conta questões como vocabulário, sintaxe, autoridade, etc: https://www.canopycanopycanopy.com/contents/international_art_english. 9 Tradução minha. 
complexas, subtis ou contraditórias. Em 1930, Fernando Pessoa no seu poema Autopsicografia afirmava "O poeta é um fingidor / finge tão completamente / que chega a fingir que é dor / a dor que deveras sente”. De outro modo, também Kandinsky reverberava o paradigma artístico de Trans-verdade, postulando que quando se "trata de verdadeiras formas de arte" estas constituem "um alimento para o espírito" e o "espectador pode encontrar nelas um eco de sua alma", onde "o clima (stimmung) da obra ainda pode aprofundar e subliminar a recetividade do espectador" (Kandinsky, 1996 [1911]: 29). A ideia da arte como representação de manifestações subliminares da psique projeta-se ainda em modernistas movimentos de vanguarda como o dos surrealistas, influenciados pelos desenvolvimentos da época na psicologia (com análises ao inconsciente, à sexualidade e aos sonhos por investigadores como Freud ou Jung). Os ecos do paradigma pré-moderno de Trans-verdade, ancorado na perspetiva aristotélica, fazem-se até sentir na produção artística contemporânea. Por exemplo, quando artistas como Jeremy Deller, Francis Allÿs ou o Atlas Group recorrem a dispositivos ficcionais que refletem realidades difíceis e se apropriam de modelos (seja em arquivo de imagens ou em performativos reenactments) para representação de situações trágicas, por vezes tabu, que se querem esquecer ou que são dolorosas, mas que pela arte são enfrentadas e ganham até dimensão política (Godfrey, 2007: 145).

De acordo com Adorno, o valor cultural da arte reside precisamente no seu caráter epistémico (Erkenntnischarakter) de emocionalmente revelar verdades ocultas acerca de temáticas sombrias do Eu e da sociedade (Borgdorff, 2011: 50). Uma vez que o que identificamos como arte opera agência (Gell, 2009), são as próprias criações artísticas que se constituem como agentes mediadores de relações humanas, fomentando processos sociais. Gell postula que na sua capacidade de agência as obras de arte podem ser consideradas como "pessoas", porque há nelas uma performatividade que é extensiva de comportamentos, intenções, atitudes e ações de quem as cria. Inclusive continuam a gerar performatividades para além das pessoas que as criam, transportando uma operatividade própria. É no fundo, como se pudéssemos incorporar a arte e a arte incorporasse algo de nós e em nós. Essa noção de performatividade expandida - que nas sociedades tradicionais se exercia como uma "tecnologia do encanto" (Gell, 2009) - de certa forma implica o que se pode identificar como afeção, isto é, a capacidade dos corpos afetarem e serem afetados através das energias das suas ações e atitudes, tocando as emoções. O conceito foi desenvolvido por Espinosa - que o adotou na sua origem latina: affectio — e desde então tem sido repetidamente abordado em contextos filosóficos e psicológicos (Deleuze, 2007; Massumi, 1995).

Ora na arte contemporânea tem-se abdicado em grande medida do valor da afeção e de um stimmung emocionalmente envolvente, subliminar, sedutor. Por um lado, como oposição a um mero decorativismo ou a uma superficial 
espectacularização, onde o deslumbre das formas esteja desvinculado de um verdadeiro posicionamento existencial que possa estimular um nível filosófico mais profundo. Por outro lado, pelo paradigma dominante da "arte pela arte" levar muito do meio artístico de contra-cultura a temer suscitar algo demasiado envolvido com partes ou o todo da sociedade. Receia-se poder exercer ou ser lido como perda de autonomia num extremo ou, pelo contrário, como manipulação política através das emoções. A consequência de tantos receios é que, apesar do frequente interesse da arte contemporânea pelo político ${ }^{10}$, os seus mediadores ${ }^{11}$ de alguma forma desenvolveram atitudes críticas face a dispositivos estéticos que pelo encantamento fomentem sentimentos de entrega do espectador. Há da parte dos intelectuais o receio de que a arte veicule pelo encantamento crença em verdades, ou seja, em "regimes de verdades" ligados a projetos políticos dominantes nas suas "verdades" totalitárias (o que de facto já aconteceu no passado).

Ao desencanto defendido pelos intelectuais alia-se o interesse do status quo, que desejando que a arte não veicule crenças contrárias aos seus interesses, vê garantida essa impossibilidade enquanto a arte se mantiver num ponto que inibe desde o início veicular qualquer tipo de convicções. Comparativamente com o paradigma anterior ao Pós-modernismo em que a arte questionava profundamente o status quo, a atual situação é-lhe bastante mais confortável e amplamente incentivada. Deste modo, a partir de motivações diferentes - intelectuais receosos do poder e poderes receosos de o perder - ambos convergem na distanciação à possibilidade da arte incluir envolvimentos mais vincadamente emocionais. Como resultado temos “artistas comprometidos? Talvez"!12

10 Veja-se como por exemplo na referencial Bienal de Veneza 2015, o curador Okwui Enwezor assumiu um posicionamento político mais vincado do que o habitual, comissariando obras como a performance/ instalação do artista Rirkrit Tiravanija, onde se produziam tijolos com caracteres chineses apelando a que não se trabalhe (à venda ao público por 10 /cada, revertendo o dinheiro para uma organização não-governamental de apoio à luta pelos direitos dos trabalhadores na China).

Ver: http://www.labiennale.org/en/art/exhibition/, http://www.labiennale.org/en/mediacenter/ video/56-44.html.

11 Curadores, galeristas, críticos, académicos, museus, centros de arte, espaços independentes, etc. 12 Artistas Comprometidos? Talvez é o título de uma exposição paradigmática da problemática em causa. Esteve patente na Fundação Calouste Gulbenkian em 2014, no âmbito do programa Próximo Futuro, com curadoria de António Pinto Ribeiro. Eis aqui excertos de uma notícia com declarações suas: “ "É hoje uma evidência o excesso de mediação entre os artistas, o público e as instituições. E isso tem uma razão de fundo que é grande diversidade e a ausência de cânones da arte contemporânea. Cabe muito do poder de selecção aos curadores. Mas o problema não são os curadores, e sim o excesso da sua influência e autoridade, que vai personificando um star-system". A este problema, acrescem outros obstáculos que desvirtuam a produção artística: "Há muitas situações de promiscuidade entre curadores, responsáveis por colecções e críticos. E isso não é nada saudável para os artistas e as programações"." O mesmo curador à pergunta de José Marmeleira: "Que sentido tem a palavra "comprometidos"?" responde que é "profundo", mas sobretudo "para a expressão de uma certa alegria, de uma ideia de festividade" e que "as obras e actividades dos artistas desta exposição não são militantes ou panfletárias". Na continuação da notícia refere que os artistas "estão inseridos num processo histórico onde o mercado e as galerias se lhes impõem, não permitindo outro tipo de orientações.”. (in Público, 20/06/2014, fonte: https:/www.publico.pt/2014/06/20/culturaipsilon/noticia/a-energia-da-inquietacao-1659534). Este é um caso exemplar de que a ausência de comprometimento na arte com qualquer tipo de crença se deve em primeiro lugar ao desejo de ausência desse comprometimento por curadores e instituições culturais. 
Promove-se na arte a dúvida, a crítica e o Talvez, mas não a adesão a crenças e verdades, que se julgam na sua ligação à sociedade inevitavelmente originarem ou serem consequência de projetos políticos. Quanto mais interventivas e politicamente eficazes essas práticas artísticas mais são apelidadas de forma depreciativa no meio da arte contemporânea como "panfletárias". A dimensão política que a arte inevitavelmente tem manifesta-se assim sob formas muito limitadas, contraditórias, "politicamente corretas” ou em teorias políticas despolitizadas de posições ${ }^{13}$. O apelo é sempre à fragmentação de verdades e não à sua busca. Privilegia-se uma arte a ser vivida com base na distanciação intelectual, idealmente mediada pelo texto, pelo curador, pela instituição cultural. O próprio "regime estético da arte" constitui "espaços neutralizados" (Ranciére, 2008: 96), onde o espaço expositivo é o mais possível neutro, luminoso, minimalista, puro e asséptico, sobrepondo-se às obras de arte (e legitimando-as) segundo a normatividade do white-cube (O’Doherty, 1999:14), portanto simultaneamente promovendo o isolamento das obras, mas sacralizando como uma igreja (integrando o legado purificador pré-moderno) de forma fria e eficaz como um laboratório científico (integrando o legado racionalista moderno). $\mathrm{Na}$ prática, o meio deve fomentar distanciação ao objeto e não adesão. Expurga-se a paixão. Expurga-se o desejo de ação do corpo. Expurga-se um verdadeiro envolvimento. Numa radicalização da arte enquanto campo autónomo, intelectual, supostamente crítico, exclui-se a afeção e o afeto ${ }^{14}$. Instalou-se desse modo, não só a dúvida, como o medo à emoção, ao afeto, à entrega. Porque desde logo não se confia no outro, não se ousa perder o controlo, estabelecer pontes, encantar e deixar-se encantar ${ }^{15}$.

\section{Um laboratório de Bio-verdade como resposta à Pós-verdade}

Perante a falta de confiança, segundo um questionador e conceptual domínio intelectual do objeto artístico, até o recetor deve ser um "espectador emancipado" (Rancière, 2008). Incentiva-se a sempre em guarda atitude cautelosa, crítica e distanciada, mesmo se de alguma forma participativa porque senão nem sequer é recetor. Contudo, será que queremos permanentemente viver emancipados, neutralizados ou descomprometidos do que nos toca?

Numa dinâmica artística comprometida com o que pretende descobrir produzem-se experiências com base em processos de participação autêntica

13 Sobre esta questão desenvolvi uma reflexão mais aprofundada no artigo Our Dreams Don't Fit In Your Ballot Boxes: An Artivist Performance in Three Acts, Revista de História da Arte, Portuguese Performance Art, n6 (2017: 90-106). Ver: http://revistaharte.fcsh.unl.pt/rhaw6/RHA_W_6.pdf

14 A própria palavra amor, como um tabu, raramente ou nunca aparece escrita num texto sobre artes visuais. Curiosamente, por contraposição, na música (da popular à erudita) tal é extremamente comum. Talvez porque as artes visuais sejam mais conceptualizadas e mediadas.

15 Basta constatar como de todos os ideais revolucionários de "Liberdade, Igualdade e Fraternidade", a fraternidade, ou seja, o amor, foi a que menos mobilizou a modernidade. Tanto na sociedade e na política, como nas artes visuais. 
face ao sentir. Nesses processos a arte busca criar experiências à parte do real mas visando o real, numa lógica experimental semelhante à que se regista em laboratório com a ciência. A diferença é que a ciência faz uma pesquisa orientada, seguindo uma hipótese que deseja comprovar e a arte pode colocar hipóteses mas é fundamentalmente movida pela livre descoberta (Rubidge 2005: 8). Há autores contemporâneos que vêm defender um regresso da arte à mítica busca laboratorial de verdade, pela capacidade da pesquisa artística produzir conhecimento, postulando inclusive uma reaproximação da arte à ciência e à experimentação (Zielinski, 2011), mas a partir da valorização do “indizível”, “sensível” e "não-proposicional” (Borgdorff, 2011).

Se o programa da pesquisa artística estivesse confinado a explicar este conhecimento não-proposicional, correria o risco, como consequência do seu olhar epistemológico, de perder o objeto de estudo pelo caminho. Correria o risco de encolher o programa a uma espécie de exercício de descodificação, tornando duvidoso se a pesquisa seria sequer útil de todo à prática artística e ao nosso entendimento da mesma(Borgdorff, 2011: 59) ${ }^{16}$.

Se intelectualmente se "exige dos espectadores que desempenhem o papel de intérpretes activos, que elaborem a sua própria tradução para se apropriarem da "história" e dela fazerem a sua própria história" (Rancière, 2008: 35), por outro lado não chegarão a tocar a emoção proposta se não se abrirem a ela. Só nos encantamos por algo que nos arrebata, que não controlamos, que nos leva a um lugar diferente do nosso domínio por intermédio da relação gerada. Não é por acaso que se diz que nos “co-movemos" quando nos emocionamos ${ }^{17}$. Ora na arte comove-nos o que nos move de encontro ao outro. E com esse outro comove-nos o indizível da mesma condição humana.

Face a uma emancipação separadora que exige uma mera conversão em "traduttori traditori", sem deixar a sensibilidade encontrar uma língua emocional comum, é discutível até que ponto se ganha ou perde liberdade e conhecimento. Seguramente dará uma sensação de poder individual, mas não de partilha, de ligação essencial. Chegar a um verdadeiro sentir revelador de uma

16 Tradução minha.

17 Tal como em inglês o que comove é "moving". 
verdadeira inquietude só é possível pelo envolvimento, pela empatia, pela busca do encontro. Essa é a ciência da arte. Uma obra executada ou recebida sem entrega, não toca o ser humano. $\mathrm{Na}$ pior das hipóteses engana. Engana-se. Perde ligação consigo e o outro, pois o sentir humano é produzido a partir da ação do corpo humano, comum a todos os humanos pelos seus sistemas biológicos com emoções comuns ${ }^{18}$. Embora seja comum e universal a capacidade dos humanos se afetarem emocionalmente uns aos outros, nunca antes as paixões humanas estiveram tão arredadas das artes visuais. Ao contrário do que acontece por exemplo com a música, que nunca abandonou a emotividade e tanto identifica minoritárias subculturas como leva enormes estádios ao delírio. Talvez essa desvinculação ao emocional tenha tornado tão pouco intensa a relação da população atual com o que a produção plástica do seu tempo oferece, diminuindo a agência da arte. Sob o ponto de vista antropológico de Gell, que postula que a arte "é um sistema de ação cujo fim é mudar o mundo" (Gell, 2009: 251), tal resulta num desempoderamento político da arte ${ }^{19}$.

Se a arte quer ter relevância individual e coletiva, ao nível experimental e filosófico-político, urge implementar o que poderíamos chamar de laboratório de bio-verdade. Ensaiando o essencial num laboratório de envolvimento sensível com participativo apuramento do autêntico, tomam-se como hipóteses vivas ao serem vividas: intuições, estímulos, sonhos, frustrações, alegrias, medos, paixões, etc. Um laboratório de bio-verdade implica o envolvimento do corpo por via de um vivo sentir. Numa busca de verdade de sentido pelos sentidos. Estimulando e experimentando o que vive em nós. Aliando pensamento e afeção do corpo. Fazendo da experiência representacional do que nos é mais vivo um meio de transportar emoções identitárias face ao que nos é interior e exterior por via simbólica. O legado moderno da razão crítica e o legado pós-moderno de conceptualização são fatores que definiram e estruturaram um enquadramento para as artes visuais, mas têm de ser doseados para não descorporalizar a presença da sensibilidade e da emoção na arte, despotenciando a sua afeção, a sua ação, o seu potencial laboratorial utópico. Nietzsche defendia "a favor da ciência estética" não só "intelecção lógica”, mas uma "duplicidade do apolíneo e do dionisíaco" (Nietzsche, 1872: 27). Note-se pois como já um dos maiores pensadores da Modernidade, redefinindo posicionamentos a partir de referentes clássicos, identificava uma necessidade de reequilibrar a arte ocidental do atual excesso apolíneo conceptual para dimensões humanas mais dionisíacas de busca de experiência e conhecimento.

18 Vários estudos científicos têm confirmado 7 emoções universais: felicidade, tristeza, surpresa, raiva, nojo, desprezo e medo. Os atores, por exemplo, usam-nas de forma empírica a partir de certas técnicas dramáticas. Exs: http://news.stanford.edu/news/2010/march/wilkins-faces-research-032510.html + https://www.sciencedaily.com/releases/2010/01/100125173234.htm

19 De salientar que a problemática política da arte não reside no uso de emoções, mas que fins serve. 
As emoções são a base de referência biológica para a atividade do cérebro e da cognição (Damásio, 2011: 213). Negá-las é negar o próprio poder da arte. Poder nada negligenciável tendo em conta o potencial transformador de nos tocar. Tocar de forma harmoniosa ou conflituosa em algo profundo, sensível, autêntico. Algo ao qual o artista manipulando se oferece e o espectador só se envolvendo recebe. Sem essa paradoxal conexão emocional na arte, sem essa bio-verdade como laboratório, esfria-se a ligação ao calor do que é humano. Extrai-se o que anima o ser humano. Extingue-se a pulsão que aponta sentido à identidade. Ao que faz avançar. Nos faz avançar a todos, transformando-nos.

\section{A arte como espelho}

A arte opera um encontro especular entre quem deseja produzir uma obra (o artista) e quem deseja ser estimulado a partir da mesma (o espectador). Todo o artista se projeta na sua expressão artística e sendo o seu devir expressar-se, existe a possibilidade de se experimentar de forma identitária na própria experiência de interpretar o que lhe parece intimamente ressoar na relação consigo ao tentar chegar ao outro. Desse modo, o artista procura expressar íntimas interpretações na relação consigo por via do outro como reflexo, num processo de simultânea emancipação e envolvimento com as suas inquietudes. Para estabelecer uma separação onde a relação se projete é que se cria um simulacro. O qual, visando ser outra coisa, exige um corte simbólico com o real (ex: palco, plinto, moldura, título, personagem, sala em cubo branco ou caixa-preta, etc.). Mesmo em abordagens mais realistas que aproximem arte e vida (inclusive rompendo com os tradicionais dispositivos separadores), é necessário manter sempre um vínculo mínimo fora do que se considera ser real para poder continuar a existir como arte e experimentar o que de outra forma não teria lugar para ser experimentado. Essa criação simbólica de espaço imaginário opera na mesma lógica psicológica descrita por Lacan, quando a criança vive uma transformação ao assumir uma imagem que gera identificação pela experiência da apropriação imagética durante o que Lacan chamou de "estádio do espelho”. Este é um estágio psíquico compreendido entre os 6 e os 18 meses, quando a criança vai tomando consciência do seu corpo pelo inconsciente reconhecimento com a imagem que lhe é devolvida pelos outros e, em particular, pela perceção da sua própria imagem ao espelho. Essa relação com o reflexo, que sendo separado de si lhe devolve o semelhante, vai ajudar a identificar-se e simultaneamente a construir um espaço de simultânea consciência e imaginação onde se situar.

Basta compreender o estádio do espelho como uma identificação, no sentido pleno que a análise atribui a esse termo, ou seja, é a 
transformação produzida no sujeito quando ele assume uma imagem (Lacan, 1998: 94).

Portanto, quando o artista trabalha e expõe o seu imaginário de forma comprometida, de alguma forma repete-se esse mesmo dispositivo de identificação simbólica. Se estiver focado e atento, vê-se, sente-se, identifica-se ao procurar tocar o outro pela perceção duma imagem refletida onde pode conhecer, ou em maior rigor reconhecer, o seu ser humano. Nesse caso, é possível descobrir-se criando para o outro - tornando o relacional algo especular e o especular relacional - , num jogo de espelhos entre o que se interpreta e o que se expressa, essencial para um artista buscar responder às inquietações que o intrigam e mobilizam. A captação das emoções e da sensibilidade tornadas conscientes (pela interpretação) e conscientemente manipuladas intelectual e fisicamente para a criação (pela expressão) provém da ambiguidade transformadora integrada por dinâmicas entre interior e exterior ao ser. Nesse esforço que é um processo íntimo e partilhado, expressando-se interpreta, diferenciando-se assemelha-se, emancipando-se envolve-se.

A metalinguagem usada pode-se identificar como metafórica pois usam-se imagens, sons, objetos, corpos, movimentos ou palavras na experiência artística como códigos representando outras coisas além de si mesmas. Qualquer metáfora coloca duas realidades em paralelo (uma referencial e outra representativa) num ambíguo resultado único que por fazer percecionar as coisas de outra forma se torna num terceiro elemento. Há na metáfora um processo metamórfico, que une duas realidades distintas numa icónica imagem encapsulada. Por sua vez, a imagem que se cria participa na criação do que se quer representar (Goodman, 1976: 62). Portanto ela não só busca verdade, como gera verdade. No fundo reflete e amplia noutra coisa o que representa. Funciona como um jogo de espelhos em função do olhar. Depende do perfil do indivíduo e sua atitude pessoal, tal como da mentalidade coletiva e do regime escópico em que socioculturalmente se enquadra, em função do tempo e espaço em que habita. Tudo isso a arte espelha como uma mise-en-abyme entre o eu e outro.

A metáfora é, de facto, metamórfica, transformadora. "A metáfora é o nosso meio de efetuar uma fusão instantânea entre dois domínios separados da experiência numa só luminosa, icónica e encapsulada imagem (p. 4)". É provável que cientistas e artistas pensem primordialmente nesse tipo de imagens (Turner, 1969: 25) ${ }^{20}$.

A metáfora possui uma eficácia empática que afeta pontos mais sensíveis ou profundos do ser humano. De acordo com a teoria da interação semântica 
de Black, o signo do objeto representado e o signo do objeto representante fundem-se para paradoxalmente abrir novo espaço cognitivo, por via de uma sinapse criativa (Black, 1962: 24). Há uma nova ligação entre duas cognições pré-existentes que transcende numa inédita terceira cognição. A síntese metafórica cria pois novo sentido, um sentido que é de desvio à regra previamente estabelecida (Ricoeur, 1982: 3). Tendo em conta a própria etimologia desta figura de estilo central à arte, observamos que "meta" (da origem grega que se poderia traduzir para português como: para fora, mudança), mais "fora" (do grego para português: traduzir-se-ia como levar, carregar) comporta um afastamento de sentido, uma transposição, uma transferência. Metáfora significa um levar para fora. A metáfora é portanto uma linguagem de mudança que exerce efetivas mudanças cognitivas, estando vinculada à ideia de movimento. Aristóteles identificava essa dinâmica como sendo de substituição, mas a moderna psicologia postula que é de interação geradora de nova combinação com “impertinência semântica” (Ricoeur, 1982: 4).

O linguista Roman Jakobson vem, no entanto, defender que embora as teorias académicas se tenham centrado sobretudo em torno da importância da metáfora, é importante distinguir a sua metalinguagem da metalinguagem da metonímia. Comparando, ambas levam a processos de transformação de sentido, mas a metáfora rege-se pelo princípio da semelhança, a metonímia, que tem sido menos estudada, obedece ao princípio da contiguidade, substituindo um elemento por outro, de forma mais direta, com base numa relação de proximidade conceptual (Jakobson, 1956: 129). Segundo este autor a metáfora está portanto presente em linguagens poéticas e pode-se ligar mais a uma abordagem romântica, enquanto por outro lado a metonímia está mais presente na produção realista, destacando-a particularmente ao nível da prosa literária (Jakobson, 1956: 132). Metáfora e metonímia podem, no entanto, identificar-se como construção frásica complementar, estando os processos linguísticos de "seleção" baseados no fator semelhança — ou seja, na metáfora, - e os processos de "combinação" no fator contiguidade — isto é, na metonímia. Para compor uma frase ${ }^{21}$ é necessário "seleção" — separar em paradigma (ex: palavras, imagens, etc) — e "combinação" — articular em sintagma (ex: sintaxe, sequência de planos, etc) (Jakobson, 1956: 115). Tal vai de encontro aos princípios psicológicos de "condensação" e “deslocação" no íntimo inconsciente, inicialmente classificados por Freud para a mente humana, mas que Lacan veio depois articular com os de "seleção" (metáfora) e "contiguidade" (metonímia), apropriados dos estudos linguísticos de Jakobson e presentes no já referido "estádio do espelho". A experiência refletida que o exercício de significação relacional faculta, para gerar identificação necessita de ir condensando 
e deslocando o espaço entre o ser e a imagem criada em torno do outro. A consciência percebe (condensa / interpreta) e age (expande / expressa) simultaneamente separada e ligada do resto do mundo, em dinâmicas dedutivas (pela interpretação) e performativas (pela expressão), que geram nos seus agentes processos de identificação.

Resumindo, a arte enquanto dispositivo criativo permite um jogo de reflexos entre dois polos: um polo agenciador de separações e um polo agenciador de condensações. Tal gera reações paradoxais entre a afirmação (onde a dinâmica de separação valoriza elementos como originalidade, autoria, liberdade de expressão, diferenciação, empoderamento ou ruptura) e o desejo de entrega (onde a dinâmica de condensação implica elementos como partilha, exposição ao outro, empatia, comoção, contemplação ou afeção). Esse refluxo entrecruzado da arte deve ser equilibrado e não estar apenas focado em dinâmicas de separação, afirmando permanentemente autonomia, eminentemente razão e exclusivamente crítica. O paradoxo de condensação e expansão da arte necessita de descolonizar-se do domínio da lógica - estruturante da Modernidade e Pós-modernidade - como o único meio válido de produção de conhecimento (até porque frequentemente serve fins emocionais de poder). A Pós-verdade e a extremada emancipação implicam tal afastamento que esvaziam o poder da arte. Inibem a arte de ser afeção interior-exterior, encontro complementar, busca ativa por uma correspondente entrega. Inibem o laboratório sensível dum mútuo (re)conhecer do que os sentidos intuitivamente já conhecem, daquilo a que atribuem sentido. E se faz sentido aos sentidos é uma forma de verdade. Como a fome ou a alegria. A dor ou o encantamento. A injustiça ou a paz.

A experiência de estar vivo, antes de ser conceito é corpo. É bio-verdade. E as experiências de reconhecimento sensível pela arte - do eu, do outro, do mundo - geram-se no seu potencial especular. O desafio é converter o potencial em capacidade, o sensível em consciência, a experiência em espelho.

\section{Referências bibliográficas}

ARISTÓTELES (1984), Poética, Souza, Eudoro de (Trad.) São Paulo, Ed. Abril

BELTING, Hans (1987), The End of the History of Art?, Wood, Christopher (Trad.), Londres e Chicago, The University of Chicago Press (obra original publicada em 1983)

BAXANDALL, Michaell (1991), O Olhar Renascente: Pintura e Experiência Social na Itália da Renascença, Almeida, Maria (Trad.), Rio de Janeiro, Ed. Paz e Terra. [Online], disponível em: https://pt.scribd.com/doc/57970484/BAXANDALL-Michael-O-olhar-RenascentePintura-e-Experiencia-Social-da-Italia-da-Renascenca [consultado em: 29/08/2017].

BERGER, P.; Luckmann, T.; Granovetter, M. e Garfinkel, H. (2004), A Construção Social da Realidade, Floriano, Fernandes (Trad.), obra original publicada em 1985, Petrópolis, Vozes.

BLACK, Max (1962), Models and Metaphores: Studies in Language and Philosophy, Ithaca: Cornell University Press.

BORGDORFF, Henk (2011), “The Production of Knowledge in Artistic Research”, The Routledge Companion to Research in the Arts, Londres e Nova Iorque, Routledge Ed. 
DAMÁSIO, António (2011), O Erro de Descartes: Emoção, Razão e Cérebro Humano, obra original publicada em 1994, Lisboa, Temas e Debates - Círculo de Leitores.

FOUCAULT, Michel (1975), Surveiller et Punir, Paris, Editions Gallimard.

FOUCAULT, Michel (1994), Dits et Écrits, IV, Paris, Editions Gallimard.

GEERTZ, Clifford (2000), “Arte como Sistema Cultural”, O Saber Local, p. 142-181, Petrópolis, Vozes.

GELL, Alfred (1998), Arte e Agência: Uma Teoria Antropológica da Arte (Trad. Britto, Paulo Henriques). Obra original publicada em 1998. Revista Poiésis, nº 14.

GODFREY, Mark (2007), “The Artist as Historian”, October 120, Spring, pp. 140-72.

GROYS, Borys (2014), “On Art Activism”, e-flux, Journal \#56, [Online], disponível em: http:// www.e-flux.com/journal/56/60343/on-art-activism/ [consultado em: 29/08/2017].

GROYS, Borys (2016), “The Truth of Art”, e-flux, Journal \#71, [Online], disponível em: http:// www.e-flux.com/journal/71/60513/the-truth-of-art/ [consultado em: 29/08/2017].

GOODMAN, Nelson (2006) “A Realidade Recriada”, Linguagens da Arte, Murcho, Desidério (Trad.), pp. 35-72, Coleção Filosofia Aberta, Lisboa: Gradiva (obra original publicada em 1976).

JACKOBSON, Roman (1988) “The Metaphoric and Metonymic Poles", Modern Criticism and Theory (Ed: Lodge, David). Nova Iorque: Longman. (obra original publicada em 1956) [Online], disponível em: http://www.mercaba.org/SANLUIS/Filosofia/ autores/Contempor\% C3\% A 1 nea/Estudios $\% 20$ de $\% 20$ filosof $\%$ C $3 \%$ ADa $\% 20$ contempor\%C3\%A1nea/Lodge,\%20David\%20-\%20Modern\%20Criticism\%20and\%20 Theory.pdf [consultado em: 29/08/ 2017].

KANDINSKY, Wassily (1996), Do Espiritual na Arte, Cabral, Álvaro, Danesi, Antonio (Trad.), obra original publicada em 1911, São Paulo, Martins Fontes, [Online], disponível em: https:// auh308.files.wordpress.com/2013/03/sem-9-kandinsky.pdf [consultado em: 29/08/ 2017].

KANT, Immanuel (1951), Critique of Judgment, Bernard, J. H. (Trad.), Nova Iorque, Hafner Publishing.

KIRCHOF, Edgar (2008), “Transmidialidade e Estilo de Oposição na Arte Pós-moderna”, I Congresso Nacional e II Regional de História da UFG - Universidade Federal de Goiás, [Online], disponível em: http://www.congressohistoriajatai.org/anais2008/doc\%20(23).pdf [consultado em: 29/08/2017].

LACAN, Jacques (1998), The Four Fundamental Concepts of Psychoanalysis, Sheridan, Allan (Trad.), Nova Iorque e Londres: Norton \& Company (obra original publicada em 1975).

LACAN, Jacques (2006) Écrits, Fink, Bruce (Trad.), Nova Iorque e Londres: Norton \& Company (obra original publicada em 1966).

NIETZSCHE, Friedrich (2012), Ciência, Gaia, Souza, Paulo (Trad.), obra original publicada em 1882, São Paulo, Companhia das Letras.

O'DOHERTY, Brian (1999), “Inside the White Cube”, The Ideology of the Gallery Space, obra original publicada em 1976, Berkeley, Los Angeles e Londres, University of California Press.

PESSOA, Fernando (1932) Autopsicografia, Presença n 36, Coimbra.

RANCIÈRE, Jacques (2010), O Espectador Emancipado, Leitão, Luís (Trad.), obra original publicada em 2008, Lisboa, Ed. Orfeu Negro.

RICOEUR, Paul (1982), Imaginação e Metáfora, Psychologie Médicale, 14 [Online], disponível em: http://www.uc.pt/fluc/uidief/textos_ricoeur/imaginacao_metafora [consultado em: 29/08/2017].

TURNER, Victor (1969), The Ritual Process. Structure and Anti-structure, Chicago, Aldine Publishing Company.

ZIELINSLI, Siegfried (2011), "Thinking About Art After the Media: Research as Practised Culture of Experiment", The Routledge Companion to Research in the Arts, Custance, Gloria (Trad.), Londres e Nova Iorque, Routledge Ed.. 